\title{
New efficient design for air-air heat pumps
}

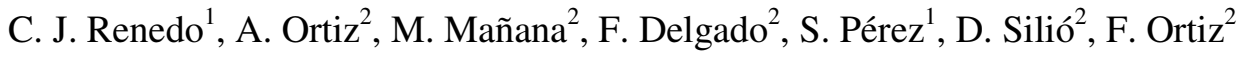 \\ ${ }^{1}$ Department of Electrical and Energy Engineering \\ ETS Náutica, University of Cantabria \\ Gamazo 1, 39004, Santander (Spain) \\ Phone/Fax number: +0034 942201344, e-mail: renedoc@unican.es, perezrs@unican.es
}

${ }^{2}$ Department of Electrical and Energy Engineering

ETSI Industriales y Telecomunicación, University of Cantabria

Av Los Castros s/n, 39005, Santander (Spain),

Phone/Fax number: +0034 942201374, e-mail: ortizfa@unican.es, mananam@unican.es

\begin{abstract}
In this work a new design for reversible air-air heat pumps is proposed. This design is based on the inversion of the air flow on the ducts, instead of the refrigerant changeover, as is proposed by ASHRAE. Thanks to this modification it is possible to use any conventional air-air refrigeration machine for air conditioning as a reversible heat pump.
\end{abstract}

The new design is more efficient, especially when a great air quality it is required in the building and therefore a larger amount of outdoor air it is used. Compared with traditional designs it also increases the efficiency as the outdoor temperatures become more extreme.

This improvement will make it possible to use heat pumps, with acceptable performances, in more rigorous climates than those in which they are used today.

\section{Key words}

reversible air-air heat pump, efficiency, return air, exhaust air, outdoor air

\section{Introduction}

Nowadays, the improvement in the quality of life has caused people to request thermal comfort and indoor air quality in buildings, independent of the outdoor conditions. This requires heating, venting and air conditioning systems (HVAC), the market for which is growing $[1,2]$ both in Spain and Europe, and whose facilities obviously have thermal generators for both cold and heat.

This thermal supply can be accomplished with chillers, heat pumps, boilers, etc., with energy consumption being higher in these elements of the HVAC system. In this way, any improvement in energy efficiency in the thermal generation results in better global efficiency. In Spain this aspect is specially relevant, since the market for new houses is the greatest in Europe [3], and the air conditioning system is offered here as an added value.

The heat pumps are machines that transfer heat from an area at low temperature to another at high temperature. This is usually carried out through the refrigeration cycle by vapour compression, taking advantage of the heat given off by the condenser instead of the heat absorbed by the evaporator.

A heat pump is reversible when advantage can be taken of the heat given off by the condenser, or the heat absorbed by the evaporator, depending on the HVAC system thermal demand.

In this way, the thermal capacity definition of a reversible heat pump $\left(\mathrm{HP}_{\mathrm{TH}}\right)$, as well as the coefficient of performance (COP), are variable from winter to summer. In winter the $\mathrm{HP}_{\mathrm{TH}} \mathrm{I}_{\mathrm{W}}$ is the heat given off by the condenser (1), while in summer $\mathrm{HP}_{\mathrm{TH}} \mathrm{I}_{\mathrm{S}}$ it is the heat absorbed in the evaporator (2). The COP in winter $\left(\left.\mathrm{COP}\right|_{\mathrm{W}}\right)$ is the quotient between the heat given off by the condenser and the work supplied to the compressor (3). In summer $\mathrm{COP}$ is defined $\left(\mathrm{COP}_{\mathrm{S}}\right)$ as the quotient between the heat absorbed by the evaporator and the work supplied to the compressor (4).

$$
\begin{gathered}
\left.\mathrm{HP}_{\mathrm{Th}}\right|_{\mathrm{W}}=\left.\dot{\mathrm{Q}}_{\mathrm{con}}\right|_{\mathrm{W}}(1) \\
\left.\mathrm{HP}_{\mathrm{Th}}\right|_{\mathrm{S}}=\left.\dot{\mathrm{Q}}_{\mathrm{eva}}\right|_{\mathrm{S}}(2) \\
\left.\mathrm{COP}\right|_{\mathrm{W}}=\left.\frac{\dot{\mathrm{Q}}_{\mathrm{con}}}{\mathrm{W}_{\text {comp }}}\right|_{\mathrm{W}}=\left.\frac{\dot{\mathrm{Q}}_{\mathrm{con}}}{\dot{\mathrm{Q}}_{\text {con }}-\dot{\mathrm{Q}}_{\text {eva }}}\right|_{\mathrm{W}} \\
\left.\mathrm{COP}\right|_{\mathrm{S}}=\left.\frac{\dot{\mathrm{Q}}_{\text {eva }}}{\mathrm{W}_{\text {comp }}}\right|_{\mathrm{S}}=\left.\frac{\dot{\mathrm{Q}}_{\text {eva }}}{\dot{\mathrm{Q}}_{\text {con }}-\dot{\mathrm{Q}}_{\mathrm{eva}}}\right|_{\mathrm{S}}
\end{gathered}
$$

The COP of a heat pump increases when the difference between condensation and evaporation temperatures decreases, since the compressor has to carry out less work to produce the same amount of heat or cold [4]. 
With respect to the standard condition of use, the greater difference of temperature between the condensation and the evaporation is in winter, which causes HPTH and COP to be greater in summer. However, this fact is compensated because the heat given off by the condenser is greater than the absorbed one in the evaporator. In this way, the HPTH and the COP of a reversible heat pump remain relatively constant throughout the year.

Currently, reversible heat pumps have a great potential, especially in climates where the winter is not actually very cold, as is the case of areas with a Mediterranean climate [5]. Thus, with practically the same initial investment that a chiller requires, it is possible to purchase a machine that is able to accomplish the thermal demand throughout the year. So, heat pumps can be an economical solution for HVAC systems in this climate.

These heat pumps are very similar to refrigeration machines, only requiring the addition of a reversing valve to invert the cycle, and a few auxiliary elements, as are check valves, or refrigerant receivers [6]. By means of the reversing valve, refrigerant flow direction is inverted, causing the condenser to become the evaporator, and the evaporator the condenser, Figure 1.
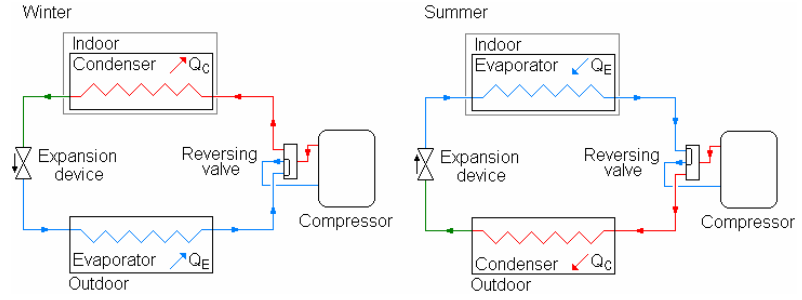

Fig 1. Reversible heat pump

In this work, a new design for a reversible air-air heat pump is proposed, studying its energy efficiency. This design improves the energy efficiency, which is specially relevant when the building requires greater air quality. The efficiency decreases as the exterior temperatures become more extreme. However, this reduction is lower in this system than in current heat pumps.

\section{Air-air heat pump}

In air-air heat pumps heat is transferred from cool air to warm air, and if it is reversible, heat or cool air could be used depending on HVAC system thermal demand. Currently, this kind of machine is very common on the market, there being a great variety of manufacturers and models $[1,7]$.

For the air-air heat pump to have high efficiency throughout the year it is necessary that the following conditions be fulfilled:

- the indoor heating system should be supplied at low temperature,

- the indoor cooling should be done at high temperature, and

- the outdoor should not have extreme temperatures, neither too low in winter, nor too high in summer.

\section{ASHRAE design}

The design proposed by ASHRAE in [8], is based on the refrigerant changeover by means of a reversing valve. This design uses two expansion valves, each of them associated to the operation of the indoor heat exchanger: as a condenser in the winter cycle, or as an evaporator in the summer cycle, Figure 2.

The indoor heat exchanger is installed in the duct by which the air is pushed into the rooms. This heat exchanger could receive recirculation air, outdoor air, or a mixture of both. Through the outdoor heat exchanger outdoor air is circulated. Afterwards, this air will be cooled in winter or warmed up in summer, it then being expelled to the outdoor. The compressor and the expansion stage are outside the ducts, Figure 2.
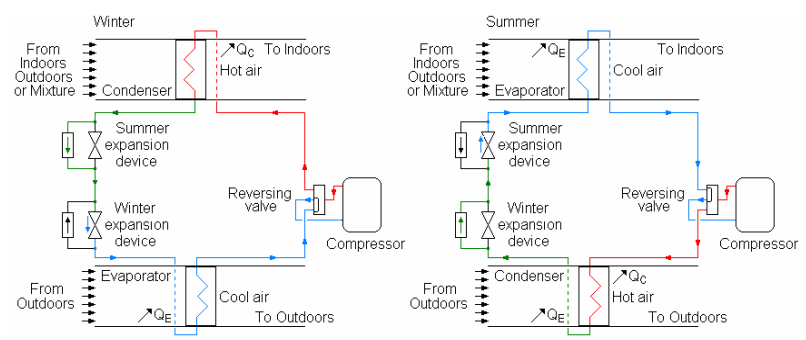

Fig 2. ASHRAE design

\section{New design}

In the new design the use of a conventional air-air machine as a heat pump is proposed. Thus, in this equipment the condenser and the compressor are in one of the ducts, just as the evaporator and the expansion device are in the other duct Figure 3.

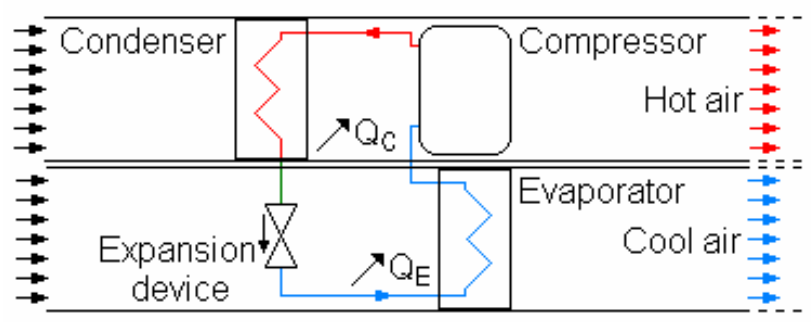

Fig 3. New design

From the energy point of view, the system is improved since in the winter cycle it takes advantage of the heat given off by the compressor, which increases the efficiency of the system. The ASHRAE design does not allow this heat to be taken advantage of. In this way, the definitions of $\mathrm{HP}_{\mathrm{TH}}$ and $\mathrm{COP}$ in summer do not vary, while in winter they are defined by (5) and (6).

$$
\left.\mathrm{HP}_{\mathrm{Th}}\right|_{\mathrm{W}}=\left.\dot{\mathrm{Q}}_{\text {con }}\right|_{\mathrm{W}}+\left.\dot{\mathrm{Q}}_{\text {comp }}\right|_{\mathrm{W}}=\left.\mathrm{HP}_{\mathrm{Th}}\right|_{\text {ASHRAE } \mathrm{W}}+\left.\dot{\mathrm{Q}}_{\text {comp }}\right|_{\mathrm{W}}
$$

$$
\left.\mathrm{COP}\right|_{\mathrm{W}}=\left.\frac{\dot{\mathrm{Q}}_{\text {con }}+\mathrm{W}_{\text {comp }}}{\mathrm{W}_{\text {comp }}}\right|_{\mathrm{W}}=1+\left.\mathrm{COP}\right|_{\text {ASHRAE } \mathrm{W}}
$$


For this machine, the conversion in the reversible heat pump, as for reversible water-water heat pumps [9], will be performed in the heat carrier fluid, in the air. For this, two systems of dampers are needed; one for the entrance ducts to the machine (from outdoors and from indoors), and another one for the exit ducts (to indoors and to outdoors), Figure 4.

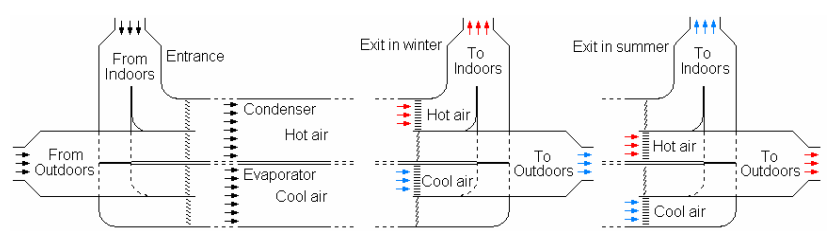

Fig 4. Design of the damper system

With respect to the damper system in the exit of the machine, in winter it allows all the air warmed up in the condenser zone to go into the rooms, while the cooled air in the evaporator goes outdoors. In summer, it allows the cooled air to be sent into the rooms and the air that has been warmed up outdoors. This operation turns the machine in a reversible heat pump.

Both damper systems can be composed of 4 dampers, Fig 4 , or 2 guillotine dampers, Fig 5. These dampers act as a three way valve, allowing the air to pass from the entrance ducts towards one of the two zones of the machine (condenser or evaporator), and then from each one of the two zones either outdoors or indoors, Figure 5.

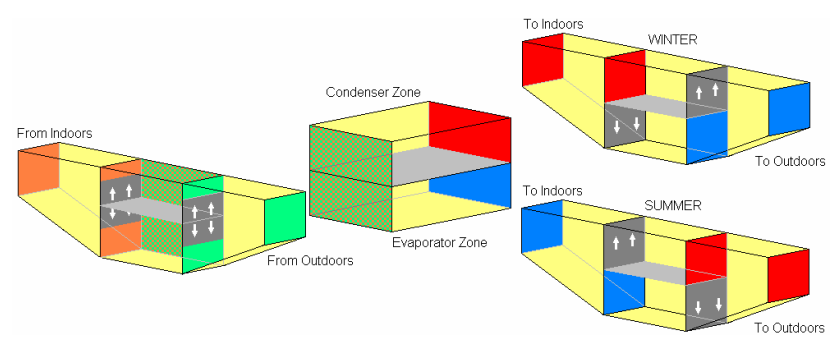

Fig 5. Reversible scheme of air-air heat pump with integrated dampers system

The damper system allows frontal, lateral, superior or inferior connection of the ducts, which facilitates the integration of the heat pump into a building's duct. In Figure 6, some of these possibilities are shown.

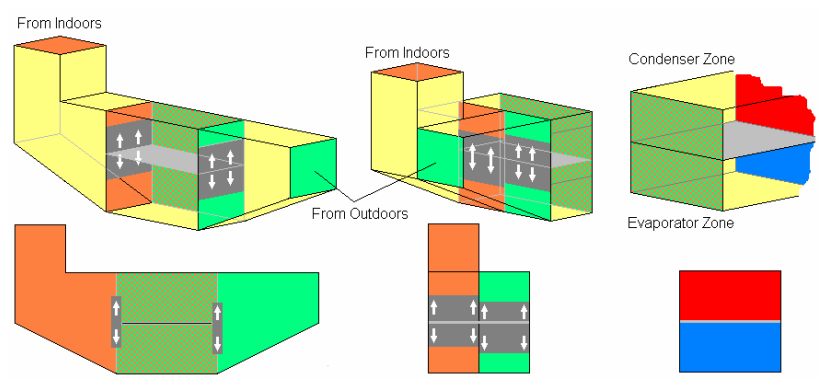

Fig 6. Several possibilities of connection of the damper systems

The exit dampers respond with a binary logic, which means that they have to completely close the passage between one of the machine zones and one of the ducts, whilst leaving the passage to the other duct totally open. The position control of these dampers is what determines the operation in winter or in summer, Figure 5.

With respect to the entrance system, it can be also composed of 4 dampers (Figure 4), or 2 guillotine dampers (Figure 5). However, in this case the movement of these dampers does not need to be boolean, but must be gradual, which allows the indoor air quality to be controlled. This method helps to vary the proportions of outdoor and recirculation air introduced into the rooms.

When only recirculation air is used in summer operation, this design presents a performance similar to the one of ASHRAE; whereas in winter the performance is improved by taking advantage of the heat given off by the compressor.

As the amount of outdoor air is increased this design shows its potential. The reason is that it takes advantage of the non recirculated air to evaporate in winter and to condense in summer. Evidently, the temperature of this air is more favourable than the one of the outdoor air (used by the ASHRAE design), so the COP of the heat pump is improved.

\subsection{Free-cooling.}

This New Design is worse than the one of ASHRAE in the periods of time in which refrigeration is required and the outdoor temperature is lower than the indoor one. In order to be able to take advantage of the free-cooling it is necessary to adapt the entrance damper system, Figure 7.

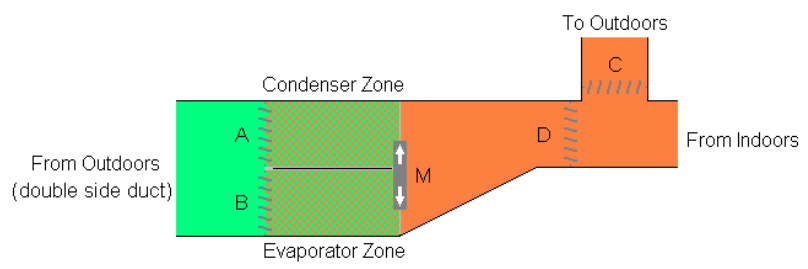

Fig 7. Free-cooling module

In the adaptation of this module, the entrance duct of outdoor air must be double size, since when free-cooling is used it has to move outdoor air that is needed to condense and to evaporate. The guillotine damper of this duct has to be replaced by two dampers that allow the gradual opening (in Figure 7 dampers A and B).

With respect to the return of the indoor air (recirculated), this air must be allowed to go towards the heat pump or out of the building. This is done with a set of dampers which could be totally opened or totally closed (in the Figure 7 dampers $\mathrm{C}$ and D).

When free-cooling is required, the dampers $\mathrm{A}, \mathrm{B}$ and $\mathrm{C}$ must remain totally open, whereas damper $\mathrm{D}$ must be totally closed. 
If free-cooling were not required, damper $\mathrm{C}$ should be totally closed, whereas damper $\mathrm{D}$ should be totally open. The regulation of the dampers $\mathrm{A}$ and $\mathrm{B}$, as the one of the guillotine damper $M$ (Figure 7), should be carried out based on the need for outdoor air and on the period of the year, summer or winter.

\section{Energy study}

An energy study has been made simulating the operation of a heat pump according to the designs of ASHRAE and the New Design proposed. Five different percentages of outdoor air have been checked: 0, 25, 50, 75 and 100\%. The considered operation parameters are indicated in Table 1 .

Table 1. Parameters for comparison

\begin{tabular}{|c|l|c|c|}
\cline { 3 - 4 } \multicolumn{2}{c|}{} & Winter & Summer \\
\hline \multirow{2}{*}{$\begin{array}{c}\text { Air temperature } \\
\left({ }^{\circ} \mathrm{C}\right)\end{array}$} & Indoor & 22 & 24 \\
\cline { 2 - 4 } & Outdoor & 0 & 40 \\
\cline { 2 - 4 } & To indoor & 40 & 17 \\
\hline $\begin{array}{c}\Delta \mathrm{T} \text { air-refrigerant } \\
\left({ }^{\circ} \mathrm{C}\right)\end{array}$ & Condenser & \multicolumn{2}{|c|}{15} \\
\cline { 2 - 3 } & Evaporator & \multicolumn{2}{|c|}{} \\
\hline Refrigerant & \multicolumn{2}{|c|}{ R134a } \\
\hline
\end{tabular}

Independently of the design of the heat pump, the input temperatures and the thermal difference in the heat exchangers determine the condensation temperature in winter and the evaporation temperature in summer. These are 55 and $2^{\circ} \mathrm{C}$ respectively.

$\mathrm{WCT}=\mathrm{W} \operatorname{ImpT}+\Delta \mathrm{T}($ Condenser - Air $)=40+15=55^{\circ} \mathrm{C}$

$\mathrm{SET}=\mathrm{S} \operatorname{ImpT}-\Delta \mathrm{T}($ Evaporator $-\mathrm{Air})=17-15=2^{\circ} \mathrm{C}$

For the ASHRAE design, the evaporation temperatures in winter and condensation in summer are fixed by the outdoor temperature and the thermal difference in the heat exchangers. They are -15 and $55^{\circ} \mathrm{C}$ respectively.

ASHRAE WET $=$ WOT $-\Delta \mathrm{T}($ Evapora tor - Air $)=0-15=-15^{\circ} \mathrm{C}$

ASHRAE SCT $=\mathrm{SOT}+\Delta \mathrm{T}($ Condenser - Air $)=40+15=55^{\circ} \mathrm{C}$

For the new design, the evaporation temperatures in winter and condensation in summer are not defined solely by the outdoor temperature and the thermal difference in the heat exchangers, since they are also influenced by the amount of recirculation air.

$$
\begin{aligned}
& \text { New Design WET }=\left(\frac{\text { WIT } .(100-\% \text { OAir })}{100}+\frac{\text { WOT } .(\% \text { OAir })}{100}\right) \\
& -\Delta \mathrm{T}(\text { Evaporator }- \text { Air })
\end{aligned}
$$

New Design SCT $=\left(\frac{\text { SIT } .(100-\% \text { OAir })}{100}+\frac{\text { SOT } .(\% \text { OAir })}{100}\right)$

$-\Delta \mathrm{T}($ Condenser $-\mathrm{Air})$
If all the recirculated air is used, all the temperatures are identical to the ASHRAE case, giving the heat pump the same COP (in winter it is increased by the heat given off by the compressor). As the proportion of outdoor air is increased, the evaporation temperatures in winter and condensation in summer are increased and decreased to 7 and $39^{\circ} \mathrm{C}$ respectively, which corresponds to the operation without recirculation air for the rooms. These temperatures are more favourable, and therefore they increase the COP of the heat pump.

In Figure 8, the results of the simulation of the COP for both designs of heat pump are shown. The operation parameters of Table 1 and five percentages of outdoor air are considered.

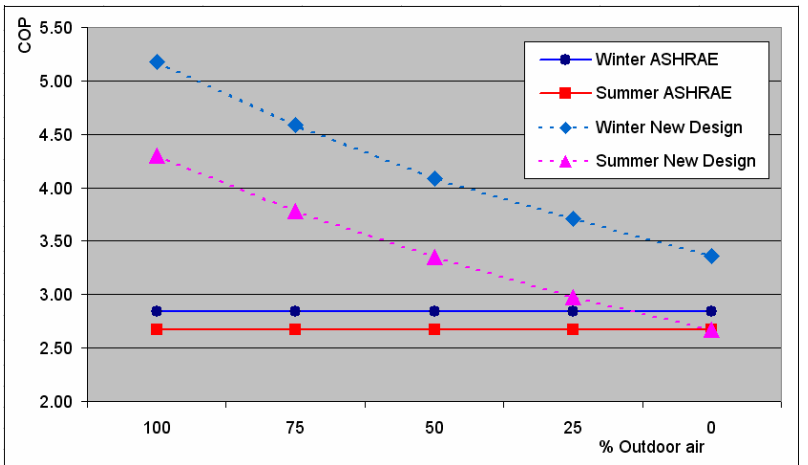

Fig 8. COP for the designs of ASHRAE and the proposed in this article

In Figure 8, it can be observed how the COP of the ASHRAE design does not depend on the percentage of outdoor air, since the condensation and evaporation temperatures only depend on the outdoor temperature and on the temperature of the air that enters the rooms. In the New Design, as the percentage of outdoor air is increased, the COP increases too, this being due to use of the energy provided by the indoor air.

As the amount of recirculated air is increased the operation resembles the ASHRAE one more closely. The cause of this is the evaporation in winter and the condensation in summer should be made with a greater percentage of outdoor air. Using all the recirculation air the COP in summer is equal for both designs. However, in winter the New Design improves upon the ASHRAE one, taking advantage of the heat given off by the compressor.

The power consumption of both designs of heat pump has been simulated. In Figure 9, the ratio New Design consumption-ASHRAE Design consumption, for the same amount of outdoor air, is shown.

From the analysis of Fig 9 some conclusions may be drawn. In winter the new design reduces the energy consumption of the ASHRAE design down to values around $55 \%$, when non recirculation air is used; this value is approximately $85 \%$ when all the indoor air is recirculated. In summer the New Design offers lower improvements, $62 \%$, when non recirculation air is used, 
and when all the indoor air is recirculated the operation is identical to the one by ASHRAE.

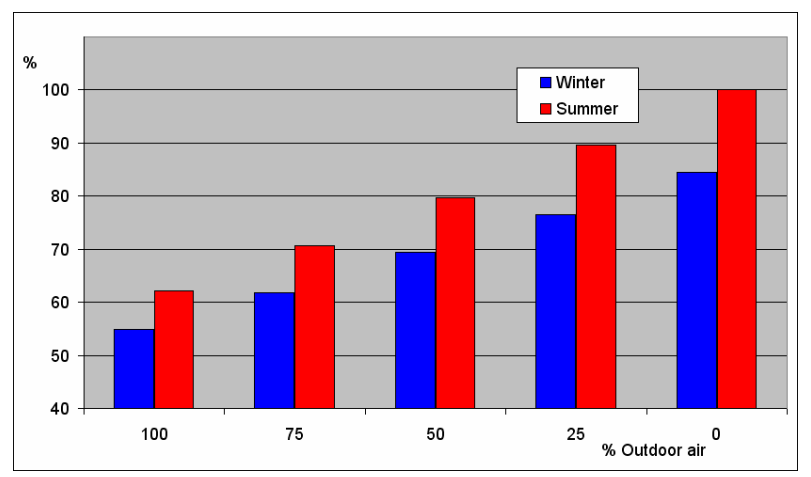

Fig 9. Energy consumption ratio New Design -ASHRAE Design, for different percentage of outdoor air

In Figure 10, the energy consumption of ASHRAE and New Designs are compared. Different climatic conditions are tested, -15 and $0^{\circ} \mathrm{C}$ in winter, and 40 and $50^{\circ} \mathrm{C}$ summer, the other parameters being maintained.

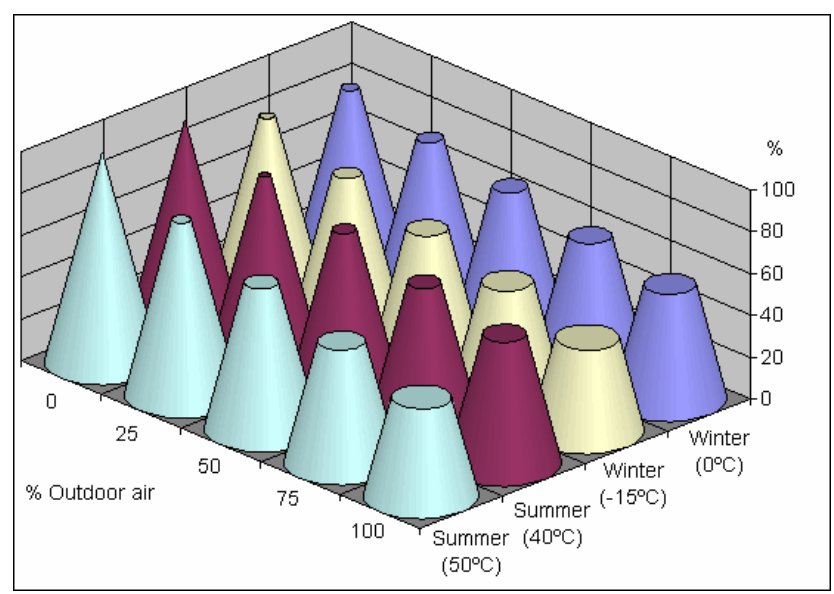

Fig 10. Energy consumption ratio New Design -

ASHRAE Design, with different climatic conditions

By observing Fig 10, it can be deduced that the more rigorous the outdoor temperatures are the greater the power benefit of the New Design for heat pumps is. This is because there is a greater difference between the temperatures to evaporate in winter and to condense in summer, with which the ASHRAE design works.

\section{Conclusions.}

In this work a new design for air-air reversible heat pumps has been proposed. The inversion of the cycle has been performed with a damper system, controlling the air in the ducts and in the heat pump heat exchangers. This design simplifies significantly the construction of the heat pump, since it is an air-air conventional machine. Thus, this allows any air-air machine to be transformed into a reversible heat pump, whether they be small devices or large-scale roof-top equipment.

The new design considerably reduces the power consumption of the design proposed by ASHRAE. This reduction is much greater when the percentage of outdoor air is increased and when the climate is more rigorous. Moreover, it is especially appreciable in winter operation, since it takes advantage of the heat given off by the compressor.

Finally, what we can conclude is that this new design transforms the equipment into an authentic power recuperator, which reaches a greater level of efficiency when more indoor air quality is required in the building.

\section{References}

[1] AFEC, http://www.afec.es/

[2] EUROVENT-CECOMAF,

http://www.eurovent-cecomaf.org/web/eurovent/web/

[3] Ministerio de la Vivienda,

http://www.mviv.es/es/index.php

[4] M.J. Moran, H. N. Shapiro, Fundamentals of Engineering Thermodynamics, Ed John Wiley \& Sons, Inc.

[5] IDAE, http://www.idae.es/

[6] HVAC Systems and Equipment, ASHRAE, 2000

[7] ENEBEC, http://www.enebc.org/

[8] HVAC Systems and Equipment, ASHRAE, 2000

[9] C.J. Renedo et al, Energy and Buildings, (38) 2006 1240-1247 